\title{
Meiotic recombination between two polymorphic restriction sites within the $\beta$ globin gene cluster
}

\author{
J M OLD, C HEATH, A FITCHES, S L THEIN, A J JEFFREYS*, \\ M PETROU $†$, B MODELL $\dagger$, AND D J WEATHERALL \\ From the National Haemoglobinopathy Reference Centre and MRC Molecular Haematology Unit, \\ Nuffield Department of Clinical Medicine, John Radcliffe Hospital, Oxford; * the Department of Genetics, \\ University of Leicester, Leicester; and the Department of Obstetrics and Gynaecology, University College \\ Hospital, Rayne Institute, London.
}

SUMmaRY Analysis of $\beta$ globin gene haplotypes for prenatal diagnosis of $\beta$ thalassaemia has revealed a recombination event within the $\beta$ globin gene cluster. Both a change in the AvaII polymorphic site within the $\beta$ globin gene and a change in the phenotype of the $\beta$ globin gene were observed. Paternity was established by the pedigree analysis of hypervariable 'minisatellite' DNA polymorphisms and the most probable explanation of the recombination event is a crossover between the $\psi \beta$ globin gene and the $\beta$ globin gene. The data provide direct evidence in support of a DNA region $3^{\prime}$ to the $\beta$ globin gene with a recombination frequency much higher than expected, and have important implications for the prenatal diagnosis of $\beta$ thalassaemia by linked restriction fragment length polymorphisms.

Polymorphic restriction enzyme recognition sites resulting from differences in the DNA sequence occur approximately once in every 100 to 200 base pairs in the normal population. These can be detected by Southern blotting because they generate DNA fragments of variable sizes after digestion with restriction enzymes. Restriction fragment length polymorphisms (RFLPs) are inherited in a simple Mendelian manner and can be used as markers to detect chromosomes carrying either normal or abnormal genes. ${ }^{2-4}$

When RFLPs are used for prenatal diagnosis of hereditary disorders, there is always the possibility of error due to meiotic recombination between the polymorphic restriction site and the particular gene of interest. In the case of the haemoglobinopathies, the polymorphic restriction sites that are used are within 20 kilobase pairs $(\mathrm{kb})$ of the $\beta$ globin gene. Unless there are 'hot spots' for recombination within the $\beta$ globin gene cluster, if $10^{6}$ base pairs equaI 1 centiMorgan the frequency of meiotic recombination should be approximately only 1 in 2000 meioses. ${ }^{5}$ However, studies of the arrangements of the RFLPs in this cluster suggest that it may contain a region of this type. ${ }^{6}$

In this paper we present the evidence for a

Received for publication 11 May 1985

Revised version accepted for publicatioin 4 July 1985 crossover between the $\psi \beta$ globin pseudogene and the $\beta$ globin gene in a child of a family with $\beta$ thalassaemia. Eight polymorphic restriction sites were analysed in each family member in order to establish the linkage of the RFLPs to the normal and $\beta$ thalassaemia chromosomes. The crossover was detected during a first trimester diagnosis and although it could not be established whether crossing over had occurred in the fetus or in an affected sib, a full pedigree analysis permitted a diagnosis of $\beta$ thalassaemia trait which was later confirmed by fetal blood sampling. Paternity was established by analysis of the inheritance pattern of tandem repetitive 'minisatellite' DNA polymorphisms. ${ }^{78}$

\section{Materials and methods}

Peripheral blood samples were collected into heparin from the family and relatives of a Turkish Cypriot couple requesting a first trimester diagnosis of $\bar{\beta}$ thalassaemia, and DNA was prepared as previously described. ${ }^{9}$ Fetal DNA was similarly prepared from a chorionic villus biopsy after gentle homogenisation of the villi in a microtissue grinder. The villus biopsy was taken at nine weeks' gestation by transcervical aspiration under the guidance of ultrasound. ${ }^{10}$ The fetal DNA was further purified by precipitation with spermine to ensure complete digestion of the DNA by restriction enzymes. ${ }^{11}$ 
The DNA samples $(5 \mu \mathrm{g})$ were digested with 10 units of each restriction enzyme and the resulting DNA fragments separated according to size by electrophoresis in a submerged horizontal $0.8 \%$ agarose gel. The gels were Southern blotted onto nitrocellulose filters and the filters hybridised to nick translated ${ }^{32} \mathrm{P}$ labelled probes, washed, and autoradiographed as previously described. ${ }^{9}$

To define the eight $\beta$ globin gene cluster RFLPs which make up the haplotype (as shown in fig 1), DNA was digested with HindII, HindIII, AvaII, and $B a m \mathrm{HI}$ and hybridised to the following probes: an $\varepsilon$ globin gene probe (p $\varepsilon 1.3$, a $1.3 \mathrm{~kb}$ Bam $\mathrm{HI} /$ EcoRI $\varepsilon$ globin gene fragment subcloned in PBR322); a $\gamma$ globin gene probe (pHd 3.2, a $3.2 \mathrm{~kb}$ HindIII ${ }^{\mathrm{A}} \gamma$ globin gene fragment subcloned in PBR322); a $\psi \beta$ globin gene probe (a $1.8 \mathrm{~kb}$ $B g l \mathrm{II} / \mathrm{XbaI}$ fragment from the recombinant plasmid pP3.9); and a $\beta$ globin gene probe (a $4.4 \mathrm{~kb}$ PstI $\beta$ globin gene fragment subcloned in PBR322). The eight polymorphic sites consist of the seven sites which comprise the $\beta$ globin cluster haplotypes described by Antonorakis et al, ${ }^{12}$ plus the $A$ vaII site near the $\psi \beta$ globin gene. ${ }^{13}$

To test for paternity, DNA from the father, mother, affected child, and fetus were digested with HinfI, Southern blotted, and hybridised with a single stranded ${ }^{32} \mathrm{P}$ labelled minisatellite probe derived from the M13 recombinant $33 \cdot 15$, as described by Jeffreys et al. ${ }^{7}$

\section{Results}

DNA was analysed from a Cypriot couple and their

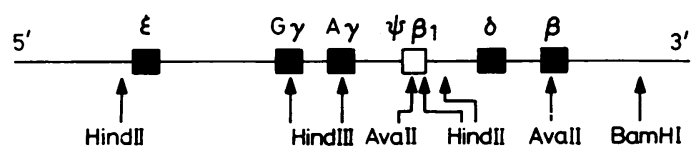

FIG 1 Map of the $\beta$ globin gene cluster showing the approximate location of the eight polymorphic restriction enzyme sites which make up the $\beta$ globin haplotype.

The Avall site in the $\psi \beta$ gene has not been precisely located and is put $5^{\prime}$ to the HindII site for convenience. previously affected child to determine the feasibility of prenatal diagnosis of $\beta$ thalassaemia. At the time of showing the mother was six weeks into her second pregnancy. Eight polymorphic sites were investigated and the results are summarised in the table. Analysis of the data showed that prenatal diagnosis would be possible because the chromosome carrying the $\beta$ thalassaemia gene in the mother (II.1, fig 2) could be identified by a ( - ) $A v a \mathrm{II}-\psi \beta$ gene RFLP, and the $\beta$ thalassaemia chromosome of the father (II.2) by the presence of the $(-+)$ HindII $\psi \beta$ gene RFLP (fig 2).

Therefore, fetal DNA was prepared from a chorionic villus biopsy and prenatal diagnosis attempted using the two linked RFLPs, plus the $A v a I I-\beta$ gene polymorphic site which was also informative. The results of these digests are shown in fig 2. At first, it appeared that the fetus was homozygous for $\beta$ thalassaemia as both the $(-)$ $A v a \mathrm{II}-\psi \beta$ and the $(-+)$ HindII- $\psi \beta$ RFLPs were found. However, the result for the AvaII- $\beta$ RFLP was $(+/+)$ indicating that the fetus was heterozygous, having inherited one normal chromosome and

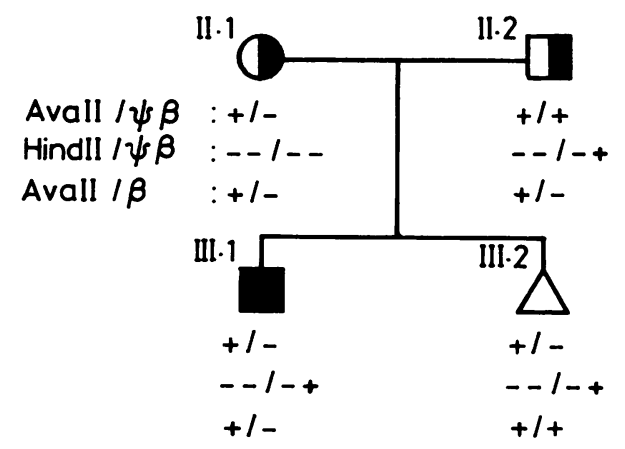

FIG 2 Pedigree of the family requesting first trimester prenatal diagnosis. Results of the initial studies for prenatal diagnosis are shown: + denotes the presence of a polymorphic site and - the absence. The shaded square indicates a male homozygous for $\beta$ thalassaemia, the half shaded circle indicates a female $\beta$ thalassaemia heterozygote, and the triangle indicates the fetus.

TABLE Analysis of eight $\beta$ globin gene polymorphic sites.

\begin{tabular}{|c|c|c|c|c|c|c|}
\hline Subject & $\begin{array}{l}\varepsilon \text { probe } \\
\text { HindII }\end{array}$ & $\begin{array}{l}\gamma \text { probe } \\
\text { HindIII }\end{array}$ & $\begin{array}{l}\psi \beta \text { probe } \\
\text { Avall }\end{array}$ & $\begin{array}{l}\psi \beta \text { probe } \\
\text { HindII }\end{array}$ & $\begin{array}{l}\beta \text { probe } \\
\text { A vall }\end{array}$ & $\begin{array}{l}\beta \text { probe } \\
\text { BamHI }\end{array}$ \\
\hline I. 1 & $-1+$ & $--1--$ & $-1+$ & $--1-+$ & $+1+$ & $+1+$ \\
\hline I. 2 & $-1+$ & $--1+-$ & $+1+$ & $--1++$ & $-1+$ & $+1+$ \\
\hline I. 3 & $-1+$ & $--1++$ & $+1+$ & $--1-+$ & $+1+$ & $-1+$ \\
\hline II. 1 & $-1+$ & $--1--$ & $-1+$ & $--1--$ & $-1+$ & $+1+$ \\
\hline II. 2 & $-1+$ & $--1++$ & $+1+$ & $--1-+$ & $-1+$ & $+1+$ \\
\hline II. 3 & $-1+$ & $--1--$ & $-1+$ & $--1--$ & $+1+$ & $-1+$ \\
\hline II. 4 & $-1+$ & $--1++$ & $+1+$ & $--1-+$ & $-1+$ & $+1+$ \\
\hline III.I & $-1+$ & $--1++$ & $-1+$ & $--1-+$ & $-1+$ & $+1+$ \\
\hline III. 2 & $-1+$ & $--1++$ & $-1+$ & $--1-+$ & $-1+$ & \\
\hline
\end{tabular}


one $\beta$ thalassaemia chromosome. This is because both parents had one chromosome with the AvaII- $\beta$ site present $(+)$ and one with it absent $(-)$, and although the linkage of the polymorphisms cannot be establishec' at this stage, if the fetus (III.2) had inherited both i; thalassaemia chromosomes in the same manner as the affected child, a similar result of $+/-$ would have been expected.

These results could be explained by crossing over at meiosis, the fetus inheriting a recombinant chromosome consisting of DNA from the $\beta$ thalassaemia chromosome on the $5^{\prime}$ side of the $\beta$ globin gene AvaII polymorphic site and DNA from the normal chromosome on the $3^{\prime}$ side.

The results were confirmed by repeating the digests on the fetal DNA and DNA from new peripheral blood samples, and then to investigate the crossover further DNA was obtained from all other relatives and a full family study completed.

The haplotypes for each family member were determined (fig 3). Those of the maternal chromosomes could be positively identified by linkage analysis and the $\beta$ thalassaemia (haplotype B) was observed to be inherited intact by both the previously affected child and the fetus. However, the haplotypes of the paternal chromosomes could not be conclusively assigned because of the incomplete pedigree, and two patterns of inheritance are equally possible.

In the first, labelled (a) in fig 3 , the paternal $\beta$

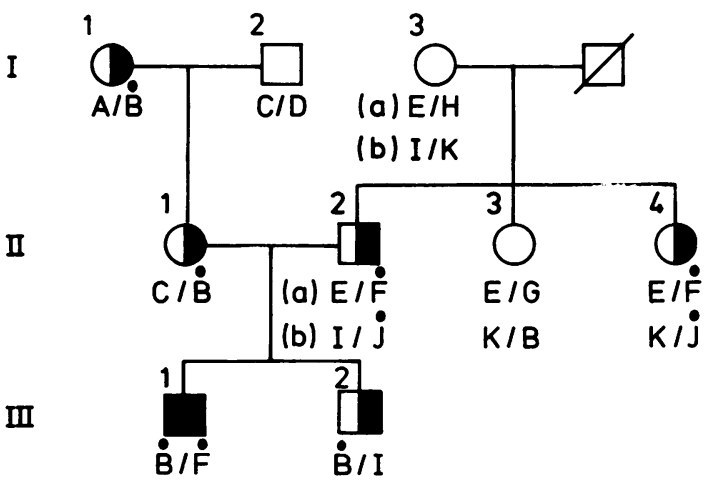

FIG 3 Extended pedigree showing the haplotypes derived by linkage analysis. The haplotypes containing a $\beta$ thalassaemia gene are marked with a spot. Because the paternal side of the pedigree is incomplete, there are two possible linkage phases, haplotypes (a) and (b).

The haplotypes are as follows, set out in the order shown in fig 1 with a gap between the 5' and $3^{\prime}$ non-randomly associated groups: $A---+-+++; B+----++$; $C+--+---+; D++-+++++; E+--+--++$; $\dot{F}-+++-+-+; G+-----+-; H-+++-++-$; $\mathrm{I}-+++-+++; J+--+---+; K+--+--+-$. thalassaemia chromosome has haplotype $F$, which has been inherited intact by the affected child (III.1). The fetus (III.2) has inherited a recombinant chromosome with haplotype I, consisting of the $5^{\prime}$ group of polymorphisms from the paternal $\beta$ thalassaemia chromosome $(-+++-+$, haplotype $F)$ and the $3^{\prime}$ group from the normal chromosome $(++$, from haplotype E). The AvaII site is located inside the $\beta$ globin gene, whereas the $\psi \beta$-HindII site is 12 $\mathrm{kb}$ upstream; therefore, it is most probable that the crossover has occurred outside the $\beta$ globin gene, and a normal gene has been inherited with the AvaII polymorphism.

Alternatively, as indicated by pattern (b) in fig 3 , the paternal $\beta$ thalassaemia chromosome has haplotype $\mathrm{J}$, and the normal chromosome haplotype $\mathrm{I}$. If this is the case, the fetus has inherited intact a normal chromosome from the father as it has the same haplotype. Therefore, it is the affected child that has inherited a recombinant chromosome, consisting of the $5^{\prime}$ group $(-+++-+)$ from the normal chromosome with haplotype I and the $3^{\prime}$ group from the $\beta$ thalassaemia chromosome with haplotype J.

In both cases the fetus would have inherited a normal $\beta$ globin gene, either on a recombinant chromosome or on an intact one. Therefore, a diagnosis of heterozygous $\beta$ thalassaemia was made and this was confirmed in the midtrimester of pregnancy by the standard method of analysis of globin chain synthesis in fetal blood obtained by fetoscopy.

Finally, because the pedigree analysis had shown that it was the paternal chromosomes which had undergone recombination in either pattern of inheritance, the results could possibly be explained by non-paternity. To investigate this possibility, the four DNA samples from the pedigree shown in fig 2 were digested with HinfI and hybridised with a probe which detects hypervariable minisatellite regions in human DNA. ${ }^{7}$ The polymorphic variation of these regions has been found to be so great that DNA from any person produces a unique band pattern, a specific DNA 'fingerprint', which can be used for paternity testing. ${ }^{8}$ The results are shown in fig 4. At least 15 of the larger HinfI fragments were resolved sufficiently in DNA from both the affected child and the fetus. All of these were clearly identifiable as either of maternal or paternal origin. For example, in the fetal DNA, seven fragments could be identified as maternal in origin and the remaining nine non-maternal fragments were all present in the DNA 'fingerprint' of the father (II.2). Since the probability that a minisatellite fragment present in a second correlated person is $\sim 0 \cdot 2^{8}$, the likelihood that II.2 by chance has all nine paternal 
fragments is $\sim(0 \cdot 2)^{9}=5 \times 10^{-7}$. Incorrect paternity of either the fetus or the affected child can therefore be rejected.

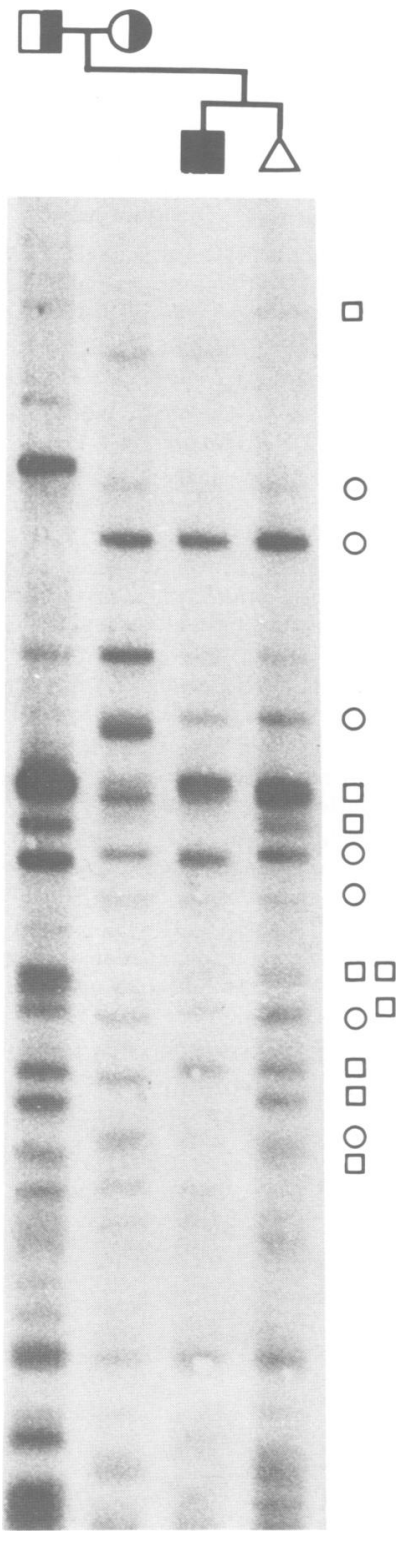

FIG 4 Southern blot showing the segregation of HinfI fragments containing hypervariable 'minisatellite' DNA regions detected by probe $33 \cdot 13 .^{7}$ Tracks 1 and 2 contain DNA from the parents, track 3 the affected child, and track 4 the fetus. The origin of the 17 largest fragments in the fetal DNA are indicated with a square for paternal origin and a circle for maternal origin.

\section{Discussion}

While carrying out first trimester prenatal diagnosis of $\beta$ thalassaemia by linkage analysis, a study of the inheritance of the $\beta$ globin polymorphism haplotypes revealed that one of the children had inherited a chromosome with a different haplotype to those found on the father's chromosomes. Although an extended pedigree analysis did not establish the precise haplotypes on each of the father's chromosomes, and therefore which subject had inherited the new haplotype, the results clearly showed that in either case the AvaII RFLP in the $\beta$ globin gene had changed, creating a new haplotype.

The change in haplotype could have arisen by a point mutation at the AvaII site. However, this explanation does not account for the associated change in the phenotype of the $\beta$ globin gene (either normal to $\beta$ thalassaemic in the affected child, or $\beta$ thalassaemic to normal in the fetus). Therefore, the occurrence of a second independent point mutation in the $\beta$ globin gene would have to be proposed, making this explanation most unlikely. A second possibility is non-paternity. However, this explanation was ruled out by the confirmation of paternity for both the affected child and the fetus by segregation analysis of hypervariable 'minisatellite' DNA polymorphisms. The final possibility is that the new haplotype was produced by a recombination event at meiosis.

It is thought that DNA recombination at meiosis involves either gene conversion or crossing over between the two chromosomes. When a crossover occurs, polymorphic markers in the DNA regions flanking the recombination site will be exchanged. However, in our case it was not possible to determine the precise mechanism of recombination. The recombination haplotype could have been generated by a gene conversion event within the $\beta$ globin gene, encompassing both the AvaII polymorphic site and the site of the $\beta$ thalassaemia mutation, in which case any flanking DNA polymorphisms would have remained the same.

Alternatively, the recombinant haplotype could have been generated by a crossover in the DNA region between the $\psi \beta$ globin gene and the $\beta$ globin gene. Because the Bam HI polymorphism $3^{\prime}$ to the $\beta$ globin gene was $(+)$ on both of the father's chromosomes, it was not possible to determine whether such a crossover had occurred.

The data presented here provide direct evidence for the occurrence of DNA recombination within the $\beta$ globin gene cluster. Our case, and a second possible recombination event recently reported by Gerhard et al, ${ }^{14}$ supports the hypothesis that a recombination hotspot occurs within a localised region of $9 \mathrm{~kb} \mathrm{5}$ of the $\beta$ globin gene. This was first 
proposed by Antonarakis and his collaborators ${ }^{12}$ who analysed the $\beta$ globin gene haplotype in various human populations and demonstrated that the polymorphic sites were non-randomly associated within two groups, one $5^{\prime}$ and one $3^{\prime}$ to the $\beta$ globin gene, but the two groups were randomly associated with each other, suggesting that the DNA region between the two groups was a site of much more frequent recombination than the surrounding DNA sequences. A more recent comprehensive study of $\beta$ globin haplotypes involving 15 polymorphic sites has suggested a recombination rate in the $9 \mathrm{~kb}$ DNA segment of three to 30 times greater than the expected figure of 1 in 2000 for the entire $\beta$ globin gene cluster. ${ }^{6}$ The DNA sequence responsible for the increased recombination frequency has yet to be ascertained and if the recombinant chromosome in our family can be positively identified, further studies may help to locate the recombination hotspot.

The finding of a recombinant $\beta$ globin haplotype has important implications in the prenatal diagnosis of $\beta$ thalassaemia. Because the recombination frequency in this region is much higher than expected, recombination is probably now the major source of error in prenatal diagnosis by RFLP linkage analysis. For a crossover to be detected, a polymorphic site must be analysed in both the $5^{\prime}$ groups of non-randomly associated polymorphic sites and the group $3^{\prime}$ to the $\beta$ globin gene. Therefore, for the prenatal diagnosis of $\beta$ thalassaemia by linked RFLPs, it is important to carry out a complete haplotype analysis of each chromosome in the family and to use polymorphisms from both the $5^{\prime}$ and $3^{\prime}$ groups whenever possible.

\footnotetext{
References

${ }^{1}$ Jeffreys AJ. DNA sequence variants in the ${ }^{\mathrm{G}} \gamma-,{ }^{\mathrm{A}} \gamma-. \delta$ - and $\beta$ globin genes of man. Cell 1979;18:1-10.
}

${ }^{2}$ Kan YW, Dozy AM. Polymorphism of DNA sequence adjacent to the human $\beta$-globin structural gene: relationship to sickle mutation. Proc Natl Acad Sci USA 1978;75:5631-5.

${ }^{3}$ Boehm CD, Antonarakis SE, Phillips JA, Stetten G, Kazazian HH Jr. Prenatal diagnosis using DNA polymorphisms: report of 95 pregnancies at risk for sickle cell or $\beta$-thalassaemia. $N$ Engl J Med 1983;308:1052-8.

${ }^{4}$ Old JM, Petrou M, Modell B, Weatherall DJ. Feasibility of antenatal diagnosis of $\beta$-thalassaemia by DNA polymorphisms in Asian Indian and Cypriot populations. $\mathrm{Br} J$ Haematol 1984:57:255-63.

5 Kurnit DM, Hoehn H. Prenatal diagnosis of human genome variation. Ann Rev Genet 1979;13:235-8.

6 Chakravarti A, Buetow KH, Antonarakis SE, Waber P, Boehm $\mathrm{C}$, Kazazian H Jr. Non-uniform recombination within the $\beta$ globin gene cluster. Am J Hum Genet 1984;36:1239-58.

7 Jeffreys AJ, Wilson V, Thein SL. Hypervariable 'minisatellite' regions in human DNA. Nature 1985;314:67-73.

8 Jeffreys AJ, Wilson V, Thein SL. Individual-specific 'fingerprints' of human DNA. Nature (in press).

${ }^{9}$ Old JM, Higgs DR. Gene analysis. In: Weatherall DJ, ed. The thalassaemias. Methods in haematology. Vol 6. Edinburgh: Churchill Livingstone, 1983:74-102.

11 Ward RHT, Modell B, Petrou M, Karajozlu F, Douratsos E. Method of sampling chorionic villi in first trimester of pregnancy under guidance of real time ultrasound. $\mathrm{Br}$ Med $J$ 1983;286: 1542-4.

11 Hoopes BC, McClare WR. Studies on the selectivity of DNA precipitation by spermine. Nucleic Acids Res 1981;9:5493-504.

12 Antonarakis SE, Boehm CD, Giardina PJV, Kazazian HH. Nonrandom association of polymorphic restriction sites in the $\beta$ globin gene cluster. Proc Natl Acad Sci USA 1982;79:137-41.

13 Wainscoat JS, Old JM, Thein SL, Weatherall DJ. A new DNA polymorphism for prenatal diagnosis of $\beta$-thalassaemia in Mediterranean populations. Lancet 1984;ii:1299-301.

${ }^{14}$ Gerhard DS, Kidd KK, Kidd JR, Egeland JA, Housman DE. Identification of a recent recombination event within the human $\beta$-globin gene cluster. Proc Natl Acad Sci USA 1984;81:7875-9.

Correspondence and requests for reprints to Dr J M Old, Nuffield Department of Clinical Medicine, John Radcliffe Hospital, Headington, Oxford OX3 9DU. 